\title{
Move-Step Analyze of the Introduction in Chinese and English Accounting Journals: Based on Analysis of Accounting Research and Journal of Accounting and Economics (2016-2018)
}

\author{
Xianrong Qiao, Ruiqi Hao \\ School of Arts and Science of Shaanxi University of Science and Technology, Translation and Cultural Communication Research
} Institute of SUST, Shaanxi Normal University, Xi'an, China

Email: 541750026@qq.com

How to cite this paper: Qiao, X. R., \& Hao, R. Q. (2019). Move-Step Analyze of the Introduction in Chinese and English Accounting Journals: Based on Analysis of Accounting Research and Journal of Accounting and Economics (2016-2018). Open Journal of Modern Linguistics, 9, 540-550. https://doi.org/10.4236/ojml.2019.96039

Received: November 19, 2019

Accepted: December 8, 2019

Published: December 11, 2019

Copyright () 2019 by author(s) and Scientific Research Publishing Inc. This work is licensed under the Creative Commons Attribution International License (CC BY 4.0).

http://creativecommons.org/licenses/by/4.0/

\section{(c) (†) Open Access}

\begin{abstract}
At present, domestic universities are paying more and more attention to publishing research papers in foreign journals, so it is very important to be familiar with the structural features of the introduction of academic papers in top English journals for writing English research papers (Hu, 2007). In this paper, John Swale's move-step analysis method was used by author, the introductions of 110 papers in the last three years (2016-2018) from the authoritative Chinese accounting journal Accounting Research and the Journal of Accounting and Economics, one of the three major American accounting journals were selected, as the research objects, and make a comparative analysis of the length of the introduction, the use frequency of each step and the writing differences. The results show that there are significant differences in the number of words and structure between Chinese and English introductions. Compared with English introductions, Chinese introductions have fewer words, and no specific steps as the framework of writing. The research results of this paper are of great significance to the writing of the introduction of accounting papers, the development of contrastive linguistics between English and Chinese, and the enrichment of textual structure research.
\end{abstract}

\section{Keywords}

Accounting Journals, Introduction Structure, Move-Step Analysis 


\section{Introduction}

With the increasing frequency of academic exchanges between China and foreign countries, the paper published in important foreign journals plays an important role in the ranking of universities and the evaluation of professional rank of scientific researchers in universities. Therefore, publishing papers in important foreign journals has attracted more and more attention from scientific researchers, and the demand is also increasing (Jiang \& Xu, 2013). For Chinese, due to the lack of English language sense and specialized English academic paper writing practices, and the lack of understanding of the differences in textual structure between Chinese and English academic papers, which led to the fact that the writing of academic papers could not meet the requirements of international academic journals and the recruitment rate was low. This paper studies the differences in the structure of the introduction of Chinese and English academic papers through the move-step analysis method, with a view to providing some reference for Chinese researchers to write the introduction of English papers.

Introduction, as the opening and important part of academic papers, plays an important role in summarizing the main idea and leading the whole text. Due to its specific genre characteristics in textual structure, genre analysts have made a lot of research. In recent years, genre-based comparative analysis of Chinese and English academic papers has received much attention in the field of applied linguistics in China. At present, the CAR model proposed by genre analyst John Swales is generally accepted internationally, CAR, namely, "Creating a research space". The research object of CARS model breaks through the limitation of previous research only at the sentence level and turns to the analysis at the textual structure level (Bian, 2012).

At present, most domestic researches have made a comparative analysis of the introduction structures of English and Chinese academic papers in the fields of engineering, animal science, medicine, law and other social and natural sciences. But it still needs to continue to explore new disciplines or subordinate disciplines of mature disciplines (Shi \& Cai, 2010). Most of them are proved from theory, without a large number of examples, lacking strong data support (Lei, 2016). This paper selects the introduction of the past three years (2016-2018) from Accounting research and Journal of Accounting and Economics, two authoritative journals in the field of Accounting in both Chinese and English. Through a comparative analysis of the introduction structures of the two representative accounting journals, this paper describes the similarities and differences in the textual structure of the introductions of Chinese and English academic papers in this field, providing some guidance and reference for Chinese accounting scholars to write English introductions (Li, 2010). The research content of this paper has made up for the deficiencies in the form and content of the introduction written and translated by Chinese researchers in the field of accounting. At the same time, it also provides some references for Chinese re- 
searchers to write English papers and translators to carry out the work of translating Chinese into English, and further promotes the internationalization process of Chinese scientific research achievements.

\section{Research Design}

\subsection{Data Collection}

The Chinese journal selected in this paper, Accounting Research, was founded in March 1980. It is the only accounting academic journal in CSSCI source journals and is recognized as an authoritative accounting journal in academia. As an authoritative English journal, Journal of Accounting and Economics, for comparative analysis, referred to as JAE, founded by the graduate school of business administration of Rochester University in March 1979, it is one of the world's top three accounting journals. In this paper, 55 paper introductions from each of the two journals were selected as data samples for analysis and were selected by random stratified sampling.

\subsection{Swales' CARS Model and Analysis Method}

Swales (1990) proposed a text analysis model for the introduction after studying a large number of empirical papers. The introduction of the paper was divided into three moves, each of which is realized by a different step. That is, step 1: establish the research field, step 2: establish the research status, step 3: occupy the research status. The three steps respectively expound the importance of the topic and make a literature review. To raise counter-questions or point out deficiencies to previous studies, or to continue previous studies. Explain the research purpose, main findings and structure of the paper. Swales' CARS introduction analysis model is shown in Table 1 (Zhang, 2016).

Table 1. CARS model of swales.

\begin{tabular}{ll}
\hline \multicolumn{1}{c}{ Moves } & \multicolumn{1}{c}{ Steps } \\
\hline Move 1 Establish the research field & 1) Put forward the central topic \\
Move 2 Establish the research status & 3) Review previous research results \\
1) Refuting the previous views \\
2) Indicating gaps or deficiencies \\
3) Asking questions \\
Move 3 Occupy the research status
\end{tabular}


Whether it is an introduction or a text, the sentences or paragraphs in the paper are not randomly transferred from one topic to another, but are organized into sentences according to the coherence of topics and the possibility of topic expansion. Move is an important concept in genre analysis. Genre analysis is to analyze the structure of a text, determine its moves and find out the rules of layout. Only in this way can the overall meaning of the text and the author's intention be deduced (Qiu, 2010).

This paper took the introduction as the research object, and finded out the similarities and differences of the textual structure of Chinese and English accounting journals according to the statistical results. From the perspective of comparative analysis, this paper comprehensively and objectively grasped the genre characteristics of the introduction in Chinese and English accounting papers, so as to reveal the preferences of Chinese and foreign authors in writing the genre structure of the introduction, and further explord the deep-seated reasons for its formation, so as to help Chinese accounting scholars to write high-quality academic papers (Chen, 2012).

\section{Statistical Results and Data Analysis}

\subsection{Comparison of the Introductions' Length Characteristics}

The length is the most obvious characteristics of the introduction. The length variables selected in this paper include the length of the article, the length of the introduction, and the percentage of the introduction to the full text (Hu, 2007). Statistical comparison of these variables can reflect the different length requirements and regulations of Chinese and English accounting journals. According to the statistical results, it can be seen from Table 2 that the average length of papers in foreign accounting journals is 43,505 words and the average length of the introduction is 4566 words. The average length of papers in Chinese accounting journals is 12,091 words and the average length of introductions is 1012 words. The average length of foreign papers is 3.5 times that of Chinese papers, while the average length of English introduction is 4 times that of Chinese introduction. This difference may be caused by the following three factors: First, the journals selected by the author were all those officially issued in China and foreign countries. Different journals have different requirements for the length of papers. Second, the introduction of Chinese acounting papers lacks some moves in writing. Third, the author's understanding and emphasis on the introduction writing are different (Niu, 2018).

Table 2. Differences in introductions' length characteristics.

\begin{tabular}{ccc}
\hline & $\begin{array}{c}\text { Journal of Accounting } \\
\text { and Economics }\end{array}$ & $\begin{array}{c}\text { Accounting } \\
\text { Research }\end{array}$ \\
\hline Number of papers & 55 & 55 \\
Average length of papers (words) & 43,505 & 12,091 \\
Average length of introductions (words) & 4566 & 1012 \\
Percentage of the introduction to full text (\%) & 15.9 & 8.3 \\
\hline
\end{tabular}




\subsection{Contrastive Analysis of English and Chinese Introduction Textual Structure}

The above research found that the differences between Chinese and foreign accounting journal papers in textual structure and writing style come from the expansion degree of each move, which leads to considerable differences in text length, namely, the introduction chapters of Chinese papers are "obviously short". In the following comparative study of Chinese and English introductions, it is found that there are great differences between Chinese and foreign authors in the process of using introduction moves (Qian \& Mu, 2017). The following text will analyze the similarities and differences between Chinese and English introductions one by one and explore the deep-rooted social and cultural reasons behind them.

The study found that there is a three-step model for introductions in Chinese and English accounting journals, and the macro-structure is basically the same, but there are obvious differences in the sequence and distribution of the moves, and there are also differences in the use frequency of the moves in English and Chinese accounting journals. Next, the frequency of each move is compared and analyzed.

\subsubsection{Move 1: The Primary Task of the Introduction of Academic Papers: "Establish the Research Field"}

The establishment of the research field as the first task of the introduction writing has been highly valued by Chinese and foreign authors, but there are significant differences in the frequency distribution of specific steps. Compared with Chinese introductions, English pays more attention to the detailed and comprehensive presentation of research fields. In the information age, efficient readers will first decide whether to continue reading the paper by reading the introduction to know whether the general content of the paper is closely related to their own research or whether it is of great significance. Therefore, the step 1-1 put forward the central topic plays a role in attracting readers. As can be seen from Table 3, the frequency of using the step 1-1 in English introductions is 50\%, and that in Chinese introductions is $40 \%$, both Chinese and foreign authors attach great importance to this step.

In move 1, the step 1-2, summarize the research content is an important step of Chinese introductions, which accounts for $81 \%$ of the frequency. In this step, the author gives a brief introduction, including the definition and research problem. In example 1, the author highlights the importance and timeliness of the topic by using some phrases that clarify the importance of the topic, such as "important issues of current concern" and "hot topics", so as to achieve the effect of quickly attracting readers' attention and stimulating their reading interest.

Example 1. Therefore, the discussion on how the convergence of accounting standards affects the comparability of financial reports is an important issue of common concern to the accounting academia and practice circles in various countries. (Convergence of Accounting Standards, Institutional Environment and Comparability of Financial Reports (Accounting Research)) 
Table 3. Differences between English and Chinese introduction moves.

\begin{tabular}{|c|c|c|c|c|c|c|}
\hline \multirow{2}{*}{ Moves } & \multirow{2}{*}{ Steps } & \multicolumn{2}{|c|}{ English introduction (55) } & \multicolumn{2}{|c|}{ Chinese introduction (55) } & \multirow{2}{*}{-Difference } \\
\hline & & Number of papers & Percentage & Number of papers & Percentage & \\
\hline Move 1 & 1-1 Put forward the central topic & 28 & $50 \%$ & 22 & $40 \%$ & $10 \%$ \\
\hline \multirow{3}{*}{$\begin{array}{l}\text { Establish the } \\
\text { research field }\end{array}$} & 1-2 Summarize the research content & 35 & $63 \%$ & 45 & $81 \%$ & $18 \%$ \\
\hline & 1-3 Review previous research results & 50 & $90 \%$ & 26 & $47 \%$ & $43 \%$ \\
\hline & 2-1Refuting the previous views & 6 & $10.9 \%$ & 0 & $0 \%$ & $10.9 \%$ \\
\hline \multirow{3}{*}{$\begin{array}{l}\text { Move } 2 \\
\text { Establish the } \\
\text { research status }\end{array}$} & 2-2 Indicating gaps or deficiencies & 51 & $92 \%$ & 15 & $27 \%$ & $65 \%$ \\
\hline & 2-3Asking questions & 4 & $7.2 \%$ & 5 & $\% 9$ & $1.8 \%$ \\
\hline & 2-4 Inheriting the tradition of research & 1 & $1.8 \%$ & 7 & $12.7 \%$ & 10.9 \\
\hline & 3-1 Overview of research purpose & 51 & $92 \%$ & 50 & $91 \%$ & $1 \%$ \\
\hline \multirow{2}{*}{$\begin{array}{l}\text { Occupy the } \\
\text { research status }\end{array}$} & 3-2 Overview of research findings & 46 & $83 \%$ & 22 & $40 \%$ & $43 \%$ \\
\hline & 3-3 Point out the structure of the paper & 50 & $90.9 \%$ & 7 & $12.7 \%$ & $78.2 \%$ \\
\hline
\end{tabular}

According to Table 3, the frequency of using step 1-3 for English introductions is $90 \%$, while that for Chinese introductions is $47 \%, 43 \%$ higher than English introductions. It can be seen that, in the English introductions, the author not only gives information on the research field in which the thesis is located, but also summarizes and evaluates the previous research results in this field, and makes a literature review by studying and analyzing a large number of research results. This requires a lot of discourse organization work. The difference in this step between the Chinese and English introductions is closely related to the research tradition at home and abroad. Western countries individualism thought was deep-rooted, emphasize individual value. Therefore, it is reflected in academic writing by reviewing the achievements of previous studies, emphasizing the contributions of previous studies and pointing out defects, so as to highlight the necessity of current studies. As shown in Example 2, when discussing previous studies, the author clearly pointed out the author of each viewpoint and emphasized the contribution of each scholar to this paper:

Example 2. Theory suggests ... For example, Stein (2002) predicts that ... through personal interactions with firms (Berger et al., 2005). In addition to bank size, theories suggest that ... (Dell'Ariccia et al., 1999; Winton, 1999). These theories suggest ... (concentration and bank expertise: Evidence from borrower financial statements (Journal of Accounting and Economics))

However, Chinese authors seldom review the previous research results, even if mentioned in the introduction, it is only a passing remark. This is mainly because Chinese culture is deeply influenced by collectivist values, advocates positive politeness strategies, reflects on academic research, especially social science research, reviews the previous research results in a rather casual and vague way, and is unwilling to discuss peer research, so as to avoid evaluating other people's achievements as much as possible. 


\subsubsection{Move 2: An Important Step in the Introduction of Academic Papers: "Establish the Research Status"}

From the comparison of step 2-1, it can be seen that the probability of refuting previous opinions in Chinese introductions is 0, in English introduction is 10.9\%. Compared with Chinese authors, English authors dare to point out the shortcomings of previous studies directly, which may be due to the differences between Chinese and western cultures. Chinese people are usually educated to avoid direct conflicts, openly criticize and discuss controversial topics. Westerners are usually willing to face problems directly, make criticisms, discuss controversial issues, and stick to what they consider to be "facts."

Example 3. These results, however, do not address the concern that ... This explanation differs from ours, as our hypothesis is that ... (Concentration and bank expertise: Evidence from borrower financial statements (Journal of Accounting and Economics))

As can be seen from Table 3, in Move 2, step 2-2 Indicating gaps or deficiencies, there is a big difference in the English and Chinese introductions. The frequency of using step 2-2 in English introductions is 92\%, that of using 27\% in Chinese introductions, the frequency difference between the two is $65 \%$. This step is related to reviewing the previous research results. After reviewing the previous research, the author will naturally point out the research aspects not covered by the previous research, and point out the differences with his own article, thus explaining the advantages of his own article. The study found that a small number of Chinese authors will point out the research gaps in the introduction, but will not point out the gap with previous papers. The reason is that the Chinese author thinks that the introduction part is to highlight the advantages of the article, and to attract readers to read by pointing out the research gaps and reflecting the innovation points of the paper. Do not pointing out the gap with previous papers is to avoid mentioning the deficiencies of the paper as much as possible. As shown in example 4.

Example 4. Although the research on financial elasticity has formed part of the research results, there are still many gaps, which are worth further exploration. (Study on the Influence of Overconfidence of Managers on Financial Elasticity (Accounting Research))

Secondly, from the difference of step 2-3, it can be seen that Chinese and foreign authors all ask questions in the introduction, and the difference is that Chinese authors are used to ask questions in the introduction and make argumentation and research in the text, while foreign authors are used to ask questions in the introduction and explain directly, as shown in Examples 5 and 6.

Example 5. Does overconfidence have an impact on financial resilience? If so, does overconfidence significantly reduce financial resilience? For different types of enterprises, is there any difference in the impact of overconfidence on financial resilience? In order to answer these questions, this paper makes an empirical study. (Study on the Influence of Overconfidence of Managers on Financial Elasticity (Accounting Research)) 
Example 6. Is either an audit verification strategy or an expertise strategy related to better performance? We find no indication either future loan charge-offs or future bank return on assets is related to audited statement collection, exposure concentration, or their interaction. (Borrower private information covenants and loan contract monitoring (Journal of Accounting and Economics))

\subsubsection{Move 3: The Last Step in the Introduction of Academic Papers: "Occupy the Research Status"}

In move 3, step 3-1 summarizes that the research purpose is an important step in Chinese introductions, mainly to illustrate the importance, necessity and innovation of writing the paper. Almost most of the papers involve this point, as shown in Example 7.

Example 7. For this reason, in order to better solve the two problems mentioned above, this paper takes 2008-2015 have export earnings of listed companies as the research object, using Heckman two-stage regression method, the test is commonly used in the exchange rate risk management practices of six financial and business use situation and using effect of hedge means, and further investigates the currency impact degree of each hedge risk management effect of differentiation. (Risk Hedging Means, Exchange Rate Impact Degree and Risk Management Effect (Accounting Research))

In move 3 step 3-2, overview of research findings is the most common steps in English introductions. as can be seen from Table 3, the frequency of English introductions summarize research findings is $83 \%$, and the frequency of Chinese introductions is $40 \%$, the difference between the two is $43 \%$, which shows that English papers emphasize the value of research, and the vast majority of papers will directly and clearly indicate the main findings of research, i.e. contributions and innovations, and explain the specific research process and problem hypothesis in the introduction part. However, the description of research findings by domestic scholars tends to attract readers' attention to the research value, understand the research significance, and have the characteristics of recommend papers. As for the specific research process and problem hypothesis, the readers will explore it by themselves in the text. As shown in examples 8 and 9

Example 8. Our study makes two contributions. First, it furthers our understanding of ... We advance this line of work by showing how a bank's expertise relates to its screening and monitoring activities, and examining different channels through which banks use and develop expertise. (Are concentrated banks better informed than diversified ones? (Journal of Accounting and Economics))

Example 9. This paper finds that the convergence practice of accounting standards in China significantly improves the comparability of financial reports with other markets, and institutional factors will affect the convergence effect of accounting standards, but the improvement of comparability does not achieve the purpose of promoting the cross-regional flow of capital. ((Convergence of Accounting Standards, Institutional Environment and Comparability of Financial Reports (Accounting Research)) 
As can be seen from Table 3, the Chinese and English introductions show great differences in the structure of the paper. $90.9 \%$ of the English introductions describe the structure of the paper, while only $12.7 \%$ of the Chinese introductions. Introducing the structure of the paper can help readers to grasp the context of the paper, better understand the author's thinking, and thus more clearly grasp the method and process of the author's argumentation. In addition, the structure of the paper can enable readers to read the article more pertinently, study the parts that interest them selectively and emphatically, and determine the key points of their reading in the introduction part. This step of the paper structure is usually connected in English introductions with the words first, second, then, next, third, consistent, finally indicating sequence and result, and always takes up multiple paragraphs to describe it, so that readers have a clear concept of the whole paper. However, most Chinese authors only make a brief statement in order to avoid the introduction being too long. As shown in Example 10:

Example 10. The structure of the rest of this paper is as follows: the second part is theoretical analysis and research hypothesis; The third part is research design; The fourth part is the result and analysis; The fifth part is robustness test. Finally, conclusions and recommendations. (Empirical Analysis of Cost Stickiness Difference and Its Causes of Different Levels of Companies in Pyramid Group (Accounting Research))

From these differences, it can be found that English introductions place more emphasis on the integrity and logicality of the text structure, while the logicality of Chinese introductions is obviously weak and random. There is no fixed pattern in the writing process of Chinese introductions, the key contents are different, and there are relatively few examples from foreign authoritative journals. In contrast, the English introductions are more objective in content, more real in conveying the current situation of the research field and pointing out the defects of this paper. The integrity and logicality of the text structure are stronger, thus pointing out the specific direction for future research and having more reference significance for scholars in this field.

\section{Results and Discussions}

Based on the statistics of the use frequency of 110 introductions in Chinese and English accounting journals, this paper makes a comparative analysis of the use difference of each move in the introductions with the model of CARS. The results show that there are significant differences between Chinese and English introductions in the frequency, sequence and distribution of language moves and steps. The reasons can be summarized as differences in writing methods and values.

Chinese authors do not strictly follow Swales' CARS model in their introduction writing, and there is no unified writing structure. The emphasis of each article's introduction is also different. The introduction of Chinese papers mostly focuses on introducing the research background, emphasizing the research value 
and contribution, briefly reviewing the previous research results, rarely making a literature review in the introduction, and rarely introducing the basic structure of the article. An analysis of introductions' textual structure in two journals shows that: Authors who write English papers use more moves than those who write Chinese papers, and most of the English introductions follow Swales' CARS model. English papers are more direct in pointing out the topics of the papers. Compared with Chinese papers, English introductions tend to point out the research purpose directly. In addition, the differences between Chinese and foreign cultures lead to different frequency of use of language steps in disciplines (Ye, 2008). Foreign scholars tend to write in a direct, clear and straightforward way, paying more attention to strict logic and clear organization. However, domestic scholars' writing is euphemistic and tortuous, and tends to move slowly, leaving more subjective space for readers.

Compared with the writing of English introduction, Chinese introduction has no uniform composition and fixed format. If we can also follow this procedure in the writing of introduction, it is easier to incorporate international standards in the writing of the introduction part of English papers.

The number of papers published by foreign authoritative journals is an important criterion to consider the academic level of the school. It is also very important to copy the writing style of foreign authoritative journals (Qian \& $\mathrm{Mu}$ 2017). It determines whether papers can be adopted and published. Many scholars in China have high-quality papers, but it is difficult to publish in foreign journals. The main reason is that the author is not good at imitating the paradigm of academic papers in international journals. From the above analysis, we can see that the writing style of Chinese accounting journals obviously does not conform the structural standard of foreign journals. Structural imitation is not content imitation, otherwise there is a suspicion of plagiarism. Therefore, to publish papers in authoritative academic journals abroad, we must study and imitate the textual structure of the journal first. The research mode of this paper is not only applicable to the research of the introduction of the accounting journals, but also applicable to other professional fields.

This study extends the three-step model originally used only for English introduction to the introduction of Chinese papers, enriches Swales' CARS model, and provides a basis for Chinese scholars in this field to write the introduction (Zhou \& Sun, 2018). Chinese scholars can write academic papers required by core journals according to the language signs of language steps. At the same time, the differences in textual structure between Chinese and English introductions described in this paper can help Chinese scholars better understand the requirements of English academic journals and publish relevant research papers in foreign high-level journals.

\section{Acknowledgements}

This research is a component of the "Translation+" Practical Talent Training Model with the Integration of CAT and Network, 2019 Higher Education Scien- 
tific Research Project of Shaanxi Association of Higher Education (Project No. XGH19108).

\section{Conflicts of Interest}

The authors declare no conflicts of interest regarding the publication of this paper.

\section{References}

Bian, C. X. (2012). A Contrastive Analysis of Categories of Introduction to Chinese and English Textile Academic Papers. Shanghai: Donghua University.

Chen, J. (2012). A Genre Comparative Study of Introduction to Academic Papers on Finance and Accounting. Chinese Journal, No.6, 20-21+56.

Hu, Z. Q. (2007). A Corpus-Based Contrastive Study of Discourse Construction in Chinese and Foreign Sci-Tech Periodicals. Journal of Huazhong University of Science and Technology.

Jiang, T., \& Xu, J. (2013). Genre Study of Introductions in English Legal Papers-From the Perspective of English-Chinese Contrast. Social Science Research, No. 2, 203-208.

Lei, S. Y. (2016). Move-Step Study of Introduction Corpus in English Academic Papers on Animal Science. Journal of Anhui Agricultural Sciences, 44, 255-258.

Li, H. Y. (2010). Genre Comparison of Introductions in English and Chinese Social Science Papers. Journal of Chongqing University of Technology (Social Science Edition), 24, 110-114.

Niu, G. L. (2018). A Comparative Corpus-Based Genre Analysis of Introduction to Chinese and Foreign Academic Papers. Journal of Xi'an Foreign Studies University, 26, 25-30.

Qian, J. J., \& Mu, C. J. (2017). Intersubjectivity in Cross-language Academic Communication: A Comparison of Text Patterns and Intervention Resources in English and Chinese Academic Periodicals. Journal of Xi'an Foreign Studies University, No. 4, 13-17.

Qiu, H. (2010). A Comparative Study on Evaluation Resources of English and Chinese Academic Papers Introduction. Hangzhou: Zhejiang University of Industry and Commerce.

Shi, S. L., \& Cai, X. (2010). A Contrastive Study on the Textual Structure of Introductions in English and Chinese Academic Papers in Engineering. Journal of Xianning University, 30, 92-94.

Swales, J. M. (1990). General Analysis-English in Academic and Research Settings (pp. 140-142). Cambridge: Cambridge University Press.

Ye, N. (2008). A Contrastive Analysis of Abstracts and Introductions in English and Chinese from the Perspective of Lexical Sets-Taking Economic Academic Papers as an Example. Journal of Jiangnan University (Humanities and Social Sciences Edition), 7, 97-103.

Zhang, X. (2016). Comparative Analysis of Introduction Parts of Chinese and English Medical Journal Papers. Chengdu: University of Electronic Science and Technology.

Zhou, W. W., \& Sun, Q. Y. (2018). A Comparative Study on the Writing of Introductions of Periodical Papers by Chinese and Foreign Scholars; Metadiscourse Perspective. Journal of Adult Education, No. 4, 83-85. 